\title{
EXPERIMENTAL INVESTIGATION OF A PARAFFIN BASED HYBRID ROCKET
}

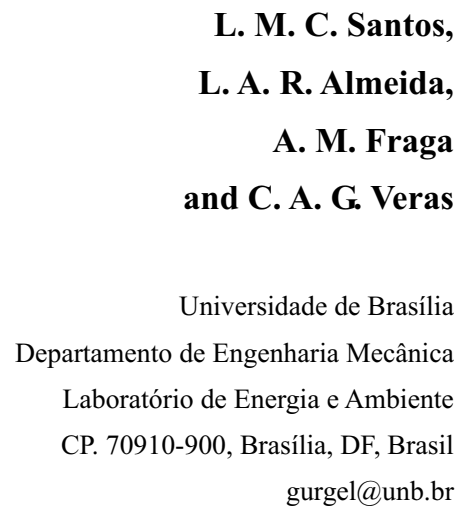

L. A. R. Almeida,

A. M. Fraga

\section{NOMENCLATURE}

$D \quad$ solid fuel internal diameter, $\mathrm{cm}$

$F$ fuel mass flow

$G_{0} \quad$ oxidizer mass flux, $\mathrm{kg} / \mathrm{m}^{2} \mathrm{~s}$

$L \quad$ solid fuel length, $\mathrm{cm}$

$L / D$ solid fuel length to internal diameter ratio

$O$ oxidizer mass flow

$O / F$ oxidizer mass flow to fuel mass flow ratio

$P_{c} \quad$ motor chamber pressure

$r \quad$ regression rate

\section{INTRODUCTION}

Hybrid rockets have the potential for reducing costs and greatly enhance safety as a propulsion system. Historically, hybrid rockets suffered from lower combustion efficiencies, lower density specific impulse and lower regression rates of solids. These, altogether, have limited the application of the technology up to date. In the past, research on the field was concerned mostly in the fundamental aspects of hybrid propulsion (Kulkarni \& Panda, 1980, Korting et al., 1987; Sparks, 1988). More recently, research has been conducted in many countries as to enhance fuel regression rate, investigate combustion instabilities, cryogenic injector design, fuel composition, to mention few. Krishnan (2002) summarized the research in hybrid rocket technology at various universities. It can be seen that hybrid technology is maturing in many different aspects. NASA (Program JIRAD), AMROC (American Rocket Company) and USAF (United States Air Force) are conducting the most important programs. The American Rocket Company presented in 1992, the Aquila Launch Vehicle. This is the first propulsion system (booster) based entirely in hybrid technology conceived to deliver up to $1450 \mathrm{~kg}$ of payload into low Earth orbit (185 $\mathrm{km})$.
The major groups working in hybrid propulsion around the world have reported studies on regression rate enhancement, because this parameter is identified as the downfall of the technology. As expected, most of the effort is from the United States of America.

The pyrolysis behavior of hybrid-rocket solid fuels was studied by Chiaverini et al. (1999) under rapid heating conditions. The solid fuel was hydroxyl-terminated polybutadiene (HTPB), pure and mixed with additives. They pointed that thermal pyrolysis data obtained in their study should be very useful for detailed modeling of combustion processes and performance calculations for hybrid motors. The solid fuel activation energy was found to be strongly dependent on surface temperature, but not on pressure.

Regression rate behavior of hybrid rockets was studied by Chiaverini et al. (2000); they used oxygen as the oxidizer and hydroxyl-terminated polybutadiene (HTPB) as the solid fuel. X-ray radiography was used to obtain instantaneous solid-fuel regression rate data in different axial location of the slab-geometry hybrid rocket motor. The main results of their investigation were: (i) regression rates were observed to decrease with axial location until a point where it reached a minimum from which there was an increase due to mass addition; (ii) solid-fuel regression was affected by thermal radiation; (iii) addition of ultra fine activated aluminum powder caused significant increase in the solid-fuel regression rate.

Risha et al. (2001, 2002) investigated the performance of a HTPB-based solid fuels containing nanosized energetic powder in a hybrid rocket motor. The main conclusion of their work was that the use of nano-sized energetic particles increased significantly, up to $63 \%$, the mass burning rates compared to the baseline HTPB for a $13 \%$ nano-sized powder addition at a specified average oxidizer mass flux of $133 \mathrm{~kg} / \mathrm{m}^{2} \mathrm{~s}$. Fuel regression rate investigations were also conducted by Chiaverini et al. (2001) and George et al. (2001) in hybrid rocket combustion. 
Hybrid rocket propulsion has been under investigation by the Energy and Environment Laboratory University of Brasília, since the year 2000 (Viegas \& Salemi, 2000; Navarro \& Pereira, 2002; Fraga 2003). The research started with an $800 \mathrm{~N}$ hybrid rocket, polyethylene based solid fuel, with seven combustion ports. A test stand was built and many firings were conducted. Ignition, combustion stability and overall performance were investigated (Viegas \& Salemi, 2000). The results were promising and the research advanced in estimating the solid-fuel regression rate (Navarro \& Pereira, 2002) in a broad range of burning conditions. More recently, Fraga (2003) tested the burning characteristics and performance of paraffin based solid fuels with oxygen as the oxidizer. A detailed fuel processing procedure was implemented in order to have the paraffin based solid grain. By such means, the performance of the solid fuel for static tests, upon combustion, showed to be reliable. Detailed of the fuel processing can be seen in the Experimental Apparatus section.

HTPB has been the preferred solid fuel for hybrid propulsion as the majority of experimental work shows. In the past two years, NASA and Stanford University have conducted experiments (Frolik, 2002) with paraffin as the solid fuel and they reported about three fold increase in regression rates compared to HTPB based fuels (Dornhein, 2003).

The answer for such phenomenon can be explained by the thin-film stability. Figure 1 helps to understand the process. The instability of the thin-film form waves that produce, at the tip, small droplets that are entrained and react in the central oxidizer flow. Such process is not observed when burning HTPB, polyethylene and other typical fuels for hybrid propulsion.

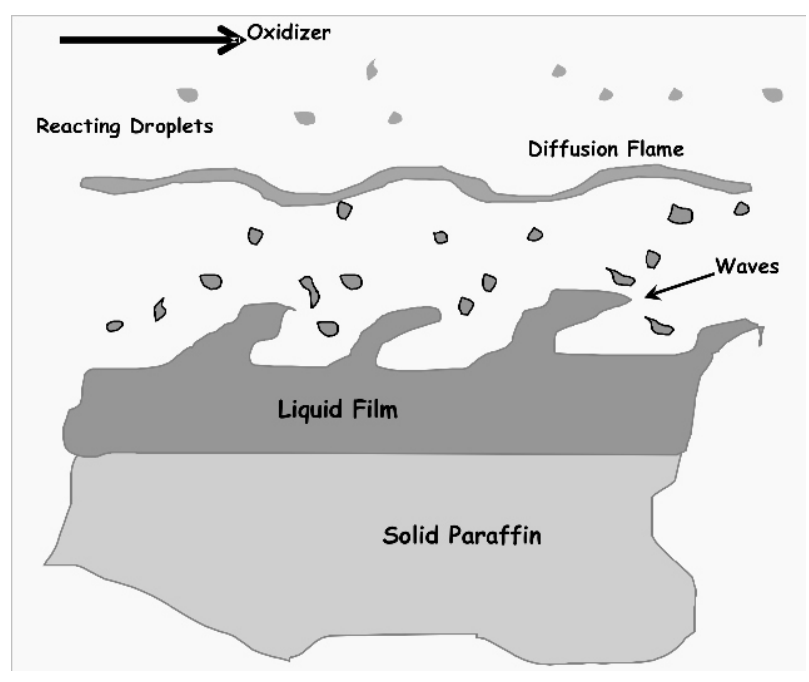

Figure 1. Thin-film instability of paraffin based solid fuel under oxidation (adapted from Dornhein, 2003).

\section{EXPERIMENTAL APPARATUS}

Figure 2 shows, schematically, the facility used for static tests. The apparatus is comprised of a $\mathrm{N}_{2} \mathrm{O}, \mathrm{O}_{2}$ and $\mathrm{N}_{2}$ tanks with distribution lines and valves (check and solenoids). Thrust and combustion chamber pressure were measured with pressure transducers. The firing control system can also be seen in the picture. The amount of oxidizer is limited by shocking the flow through the respective nozzles (critical flow). This system was used to maintain a steady state flow of oxidizer. Depending on the temperature, the $\mathrm{N}_{2} \mathrm{O}$ stagnation pressure can be that of the tank. For instance, if the tank is at $21^{\circ} \mathrm{C}$ the nitrous oxide saturation pressure is 52 bar, which is deemed, appropriated for testing the rocket. The oxidizer flow was controlled by a shocking nozzle positioned after the pressure regulator. For $\mathrm{N}_{2} \mathrm{O}$ the throat diameter was set to $5.9 \mathrm{~mm}$ for which the maximum oxidizer flow was 0.42 $\mathrm{kg} / \mathrm{s}$ that gives about $475 \mathrm{~N}$ of thrust. Due to the equivalent ratio, less oxygen is needed for the same amount of fuel. In our experiments with gaseous oxygen and paraffin, the maximum gas flux attained was estimated to be lower than $0.2 \mathrm{~kg} / \mathrm{s}$ due to valve dimension characteristics.

The facility is able to perform static tests on hybrid rockets up to $2000 \mathrm{~N}$ of thrust. The motor was built of schedule 40 steel pipe with flat steel flanges in the endings, one hosting the oxidizer injection system and the other the thrust generation device (nozzle). The solid fuel is positioned at about $5 \mathrm{~cm}$ after the oxidizer injector flange and a PVC post combustion chamber minimize the heat transfer to the motor casing. Visual observations and weighing the post chamber, prior and after firings, show that negligible reaction takes place at the surface. Therefore, little influence on overall performance of the motor is considered. Details regarding the motor can be seen in Fig. 3. The paraffin solid fuel is about $700 \mathrm{~g}$ in mass with an internal diameter of $23.0 \mathrm{~mm}$ and $22.0 \mathrm{~mm}$ of length. The fuel is prepared from commercial paraffin type "Macro Cristalina", made by Gquímica, used in candles. Carbon black powder is added to the liquid paraffin in order to prevent radiation from melting the entire grain, instead, only a thin layer is formed over the internal surface of combustion port. We used, form fuel casing, PVC tubes with threaded caps in both ends. One cap is positioned and liquid paraffin is poured through the open top end. The tube is then sealed with the second cap and rotated, trough the longitudinal axis at $1400 \mathrm{rpm}$ for about one a half hour. Centrifugal forces and solidification at very slow rate ensure a good quality grain. The internal diameter didn't have to be machined. The amount of paraffin poured is estimated by knowing the volume of the casing and the contraction factor (about 15\%). Therefore, the internal hole is obtained straightforward. The solid fuel in the PVC casing is then placed inside the motor. Finally, after introducing in the pos-combustion chamber the thermal isolator (PVC tube) the nozzle is placed along with the flanges and the motor is ready for firing.

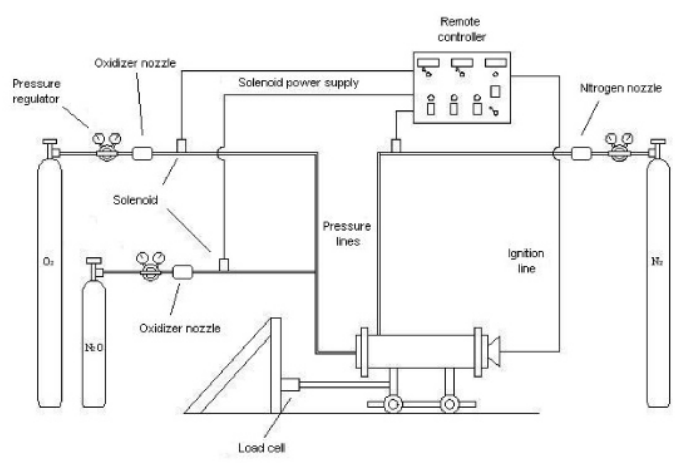

Figure 2. Test stand for hybrid rockets.

Ignition was provided by steel wool, some black powder and a piece of wire in which an electrical current is applied. This system is placed inside the grain near the oxidizer injector. 
After applying the electrical current, by means of a short circuit, the steel wool and the black powder initiated combustion and nitrous oxide is allowed to enter the motor. The nitrous oxide dissociation temperature is over $575^{\circ} \mathrm{C}$, consequently, the ignition system must provide this temperature level. In fact, we never had problems igniting the motor with either, gaseous oxygen or nitrous oxide.

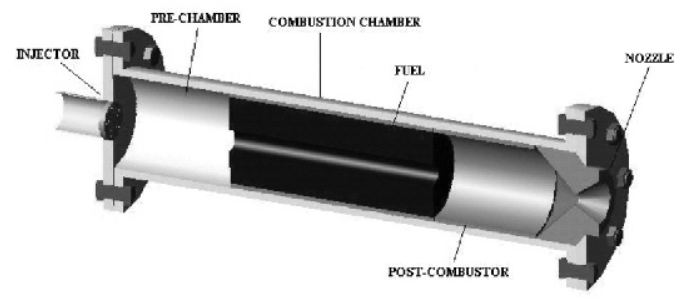

Figure 3. Hybrid motor assembly.

The pressure inside the combustion chamber and thrust measurements verified the performance of the motor. The load cell was, in reality, a pressurized device (cylinder/piston) with knowing geometric configuration. Then, by measuring pressure we could infer motor thrust. The pressure transducers were made by Wika, type Eco-1 (4 to $20 \mathrm{~mA}$ signal). Both pressure transducers were carefully calibrated. Details of the acquisition system can be seen in Fig. 4. The signal from the pressure transmitters were converted to voltage and sent to an HP model 35665 Dynamic Signal Analyzer. The signal is converted to an ASCII file that can be processed by spreadsheet software.

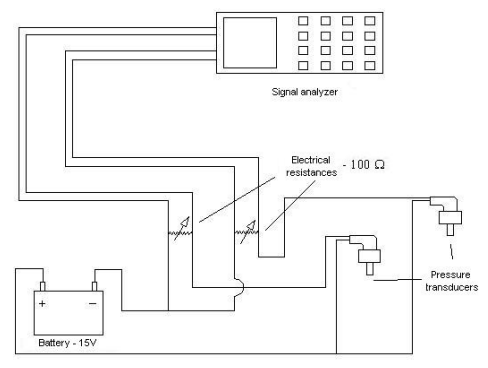

Figure 4. Data acquisition schematic.

\section{RESULTS AND DISCUSSION}

A reasonable performance was always obtained while operating the hybrid rocket, no matter the combination of fuel and oxidizer. In other words, ignition and burning of the solid fuel were attained with measured parameters closed to what was theoretically designed. In the last three years we performed more than 60 firings employing polyethylene and paraffin (pure or doped) with either gaseous $\mathrm{O}_{2}$ or $\mathrm{N}_{2} \mathrm{O}$ as the oxidizers. In this paper only the results with paraffin based solid fuel and nitrous oxidizer are discussed in more detail. We believe that this investigation represents the first results on paraffin based solid fuel and nitrous oxide hybrid rocket ever conducted in Brazil. Table 1 compares the operating conditions of this study to that for larger motors. In Table $1, G_{o}$ is the oxidizer mass flux, $L$ and $D$ are the solid fuel length and internal diameter, $O$ and $F$ are the oxidizer mass flow and fuel mass flow, respectively.
Table 1. Comparison of different hybrid rocket operating conditions (Chiaverini et al. 2000, adapted).

\begin{tabular}{|c|c|c|c|c|c|}
\hline $\begin{array}{l}\text { Param } \\
\text { eter }\end{array}$ & ELV & $\begin{array}{l}\text { Large } \\
\text { Booster }\end{array}$ & $\begin{array}{l}\text { 11- } \\
\text { Jirad }\end{array}$ & PSU & $\begin{array}{l}\text { This } \\
\text { study }\end{array}$ \\
\hline $\begin{array}{l}\text { Press } \\
\text { ure, } \\
\text { bar }\end{array}$ & $20-40$ & $27-34$ & $10-78$ & $12-54$ & $12-20$ \\
\hline $\begin{array}{l}\mathrm{G}_{\mathrm{o}}, \\
\mathrm{kg} / \mathrm{m}^{2} \\
\mathrm{~s}\end{array}$ & $\begin{array}{l}420- \\
560\end{array}$ & $\begin{array}{l}560- \\
900\end{array}$ & $\begin{array}{l}100- \\
560\end{array}$ & $\begin{array}{l}110- \\
450\end{array}$ & $\begin{array}{l}200- \\
700\end{array}$ \\
\hline $\begin{array}{l}\text { Initial } \\
\text { L/D }\end{array}$ & $26-35$ & $32-39$ & $\begin{array}{l}17.6- \\
34\end{array}$ & $25-37$ & $9-11$ \\
\hline $\begin{array}{l}\text { Average } \\
\mathrm{O} / \mathrm{F}\end{array}$ & $\begin{array}{l}2.3- \\
2.6\end{array}$ & $\begin{array}{l}2.5- \\
2.6\end{array}$ & $\begin{array}{l}1.11- \\
3.33\end{array}$ & $\begin{array}{l}1.5- \\
2.7\end{array}$ & $\begin{array}{l}8.5- \\
9.5\end{array}$ \\
\hline
\end{tabular}

ELV- expendable large vehicle, PSU Pennsylvania State University, Project Jirad (Krishnan, 2002)

In Table 1, oxygen was the oxidizer, except for this study. The average $O / F$ ratio for nitrous oxide and paraffin based solid fuel is about 9.5 for stoichiometric burning. As it can be seen, this ratio is much lower for oxygen and has some influence in the initial $L / D$ configuration, since for a given thrust, less fuel is required when nitrous oxide is used. Although small in size, our motor is able to perform tests that can have, to some extent, the performance compared to other studies, despite the fact we used a different oxidizer.

Our previous experiments with gaseous oxygen and ultra high density polyethylene in the pressure range of 2040 bar resulted in regressions rates no higher than 0.3 $\mathrm{mm} / \mathrm{s}$. The research was then shifted to paraffin as the solid fuel and gaseous oxygen. A series of experiments was conducted with oxidizer mass flux $\left(\mathrm{O}_{2}\right)$ ranging from 2 to $10 \mathrm{~g} / \mathrm{cm}^{2} \mathrm{~s}$. This low oxidizer mass flux $\left(\mathrm{O}_{2}\right)$ resulted in regression rates no higher than $1.0 \mathrm{~mm} / \mathrm{s}$. In our experiments, we were not able to increase the $\mathrm{O}_{2}$ mass flux because our pressure control valve reached critical flow. Not withstanding, this phase project was of great importance since the team got precious experience in hybrid rocket propulsion. Our main interest at that time was to improve the quality of the solid fuel, to develop a reliable ignition system and firing procedures that led to stable burning of the paraffin. In real application, solid fuel hybrid rockets need to carry the oxidizer in the liquid phase. The main purpose of our research, in the near future, is to test and demonstrate the technology by launching a sounding rocket based on paraffin and nitrous oxide.

To investigate the solid fuel regression rate we conducted more three tests with slight variation on pressure and on oxidizer $\left(\mathrm{N}_{2} \mathrm{O}\right)$ mass flux. We are currently programming a series of test to cover a broader range of varying parameters. Up to this point, however, our main objective was to evaluate the overall behavior of paraffin based solid fuel burning with nitrous oxide at very high mass flux. It is shown here the results of tests 1 and 3 because the motor performance for test $2 \mathrm{had}$ measured parameters limited by the other tests.

For further comparison, Table 2 presents a summary of lab-scale hybrid motor regression rate tested by Chiaverini et al. (2001). In the comments area of the table, X-ray and ultrasound are related to regression rates measurement system. Regarding pressure oscillations, they observed $25 \%$ variation over the mean pressure for 
test 5 , for the remaining tests displayed pressure traces were about $1 \%$. Not all the tests are listed in the table, but only those that are closer to the higher and lower values of regression rates, and those in which the fuel had been doped. As it can be seen, the highest regression rate reported was for test number 20 , averaging $1.54 \mathrm{~mm} / \mathrm{s}$, the lowest $0.72 \mathrm{~mm} / \mathrm{s}$ for test number 8 , on account of the modest oxidizer mass flux. The proposed regression rate (Chiaverini et al., 2001) equation for all the tests was

$$
r=0.049 G^{0.61}
$$

Table 2: Regression rate and burning conditions of labscale hybrid motor (Chiaverini et al. 2001, adapted).

\begin{tabular}{|c|c|c|c|c|c|c|}
\hline Test & Fuel & $\begin{array}{c}\mathrm{G}_{0} \\
\left(\mathrm{~kg} / \mathrm{m}^{2} \mathrm{~s}\right)\end{array}$ & $\begin{array}{c}\mathrm{P}_{\mathrm{c}} \\
(\mathrm{atm})\end{array}$ & $\begin{array}{c}\mathrm{D} \\
(\mathrm{cm})\end{array}$ & $\mathrm{O} / \mathrm{F}$ & $\begin{array}{c}\mathrm{r} \\
(\mathrm{mm} / \mathrm{s})\end{array}$ \\
\hline 5 & HTPB & 151.0 & 40.2 & 2.64 & 1.29 & 1.36 \\
\hline 6 & HTPB & 113.5 & 25.9 & 3.20 & 1.88 & 0.87 \\
\hline 8 & HTPB & 82.2 & 25.5 & 3.21 & 1.67 & 0.72 \\
\hline 11 & HTPB $^{1}$ & 112.9 & 30.4 & 3.39 & 2.04 & 0.92 \\
\hline 20 & HTPB $^{2}$ & 273.5 & 18.7 & 2.73 & 2.05 & 1.54 \\
\hline 21 & HTPB $^{2}$ & 174.1 & 27.3 & 3.24 & 1.96 & 1.25 \\
\hline
\end{tabular}

${ }^{1} \mathrm{HTPB}+0.25 \%$ carbon black powder, $75 \mathrm{~nm},{ }^{2} \mathrm{HTPB}+20 \% \mathrm{Al}$.

Figure 5 shows motor chamber pressure as a function of burning time for test 1 . The total fuel consumption for this test was estimated to be 618 grams. The average regression rate was $2.2 \mathrm{~mm} / \mathrm{s}$, which is higher than that reported for standard HTPB based solid fuel at the same oxidizer mass flux.

Pressure built up took less than a second. After another second solid fuel burning had been well established and progresses up to 10 seconds. The solid fuel burning appears to be quite smooth from 2.8 to 5.0 seconds. Pressure oscillation ( 1.0 bar) was stronger after $5.0 \mathrm{~s}$. Pressure decay was due to the rapid decrease in the temperature of the nitrous oxide tank, followed closed by the saturation pressure.

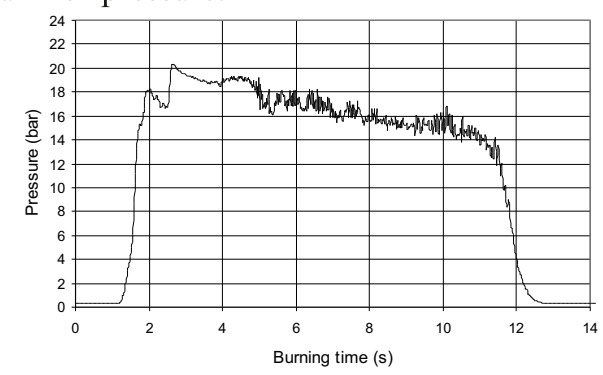

Figure 5. Motor chamber pressure (test 1).

Figure 6 shows the thrust curve for test 1 . As expected, the curve is quite similar to that of pressure. In the first 5 seconds thrust was higher that 200 N. As pressure decays thrust follows and for the rest of the burning the motor delivered more than $150 \mathrm{~N}$.

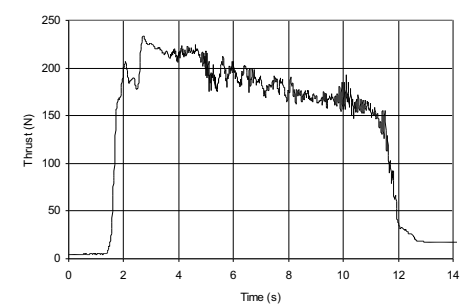

Figure 6: Thrust motor (test 1).
Figure 7 shows the motor camber pressure for test 3. Pressure built up for this test was slightly different compared to test 1 . The burning took place with motor chamber pressure ranging from 12 to 16 bar. The firing was set only few minutes after test 1 and 2 . As mentioned, tank temperature lowers due to rapid evaporation of nitrous oxide. In spite of that, the curve shows a steadier burning, compared to test 1 , with pressure oscillation of about 1.3 bar. Motor thrust follows closely chamber pressure history and the average result was at about $150 \mathrm{~N}$. Burning time for this test lastly for 13.0 seconds. Average regression rate for such performance was about $2.04 \mathrm{~mm} / \mathrm{s}$, which is also higher than the reported values for HTPB with the same oxidizer mass flux. All the three tests were taped with a digital camera. Observation of the nozzle exit section jet showed the occurrence of diamond shock waves. There were no efforts in improving motor performance by means of correcting nozzle expansion.

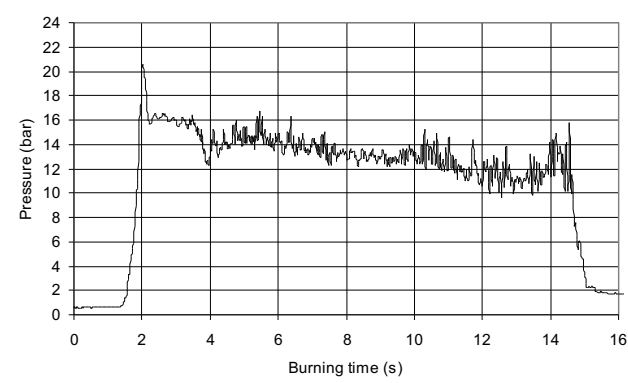

Figure 6. Motor chamber pressure (test 3).

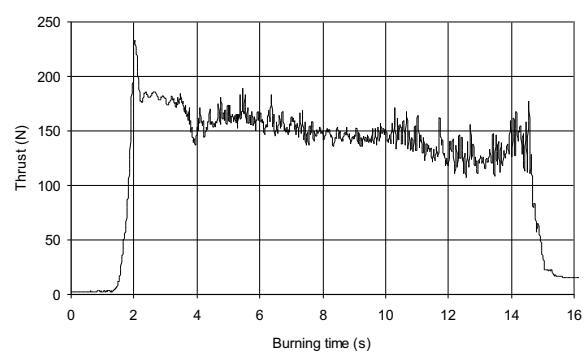

Figure 7. Thrust motor (test 3).

Motor performance of test number 3 was closed to tests 1 and 2 as expected. Average thrust measurements were of about $160 \mathrm{~N}$ and regression rate averaged 1.96 $\mathrm{mm} / \mathrm{s}$. Chamber pressure history for test number 3 was in the range of 10 to 15 bar.

Paraffin based solid fuel has shown much better performance when burned with oxygen and nitrous oxidizer compared to our experiments with polyethylene. Also, motor performance operating with paraffin and nitrous oxide showed higher regression rates compared to the data reported for HTPB fuels. In our tests, ignition and stable burn (reasonable) were always accomplished, no matter the fuel or oxidizer.

We are planning to build and test a small hybrid rocket based on paraffin as the solid fuel and nitrous oxidizer to demonstrate the technology. The technology is maturing, even in Brazil, turning hybrid an interesting option for the Brazilian Space Program.

\section{CONCLUSIONS}

The main conclusions that can be drawn from this work are: 
- Hybrid propulsion system are easy to operate in static tests;

- $\quad$ Regression rates for paraffin based solid fuel and nitrous oxide as the oxidizer are higher that those obtained in standard HTPB and oxygen reported bythe literature;

Ignition and stable burning was possible for all the firings conducted by our research team.

\section{REFERENCES}

Chiaverini, M.J., Harting, G.C., Lu, Y-C., Kuo, K.K., and Peretz, A., Pyrolysis Behavior of Hybrid-Rocket Solid Fuels under Rapid Heating Conditions, Journal of Propulsion and Power, Vol. 15, No. 6, 1999.

Chiaverini, M.J., Johnson, D.K., Lu, Y-C., Kuo, K.K. and Risha, G.A., Regression Rate Behavior of Hybrid Rocket Solid Fuel, Journal of Propulsion and Power, Vol. 16.No 1, 2000.

Chiaverini, M.J., Kuo, K.K., Peretz A., and Harting, G.C, Regression-rate and Heat-Transfer Correlations for Hybrid Rocket Propulsion, Journal of Propulsion and Power, Vol. 17, No. 1, pp. 99-110, 2001.

Dorhein, M.A., Aviation Week \& Space Technology, February 3, 2003.

Frolik, S, Aerospace América, December, 2002.

George, P., Krishnan, S., Ravindran, M., Varkey, P.M., and Ramachandran, L., Fuel Regression Rate in Hydroxyl-Terminated-Polybutadiene/Gaseous-Oxygen Hybrid Rocket Motor, Journal of Propulsion and Power, Vol. 17,.No 1, pp 35-42, 2001.

Ignition and Burning with RFNA as Oxidizer, Combustion and Flame Vol. 39, 123-132, 1980.

Korting, A.O.G., Shoyer, H.F.R., and Timnat, Y.M., Advanced Hybrid Rocket Experiments, Acta Astronáutica, Vol. 15, No. 2, pp. 97-104, 1987.

Krishnan, S., Developments and Challenges in Hybrid Rocket Propulsion, 6th Asia pacific International Symposium on Combustion and Energy Utilization, Kuala Lumpur, Malaysia, 2002.

Kulkarni, S. and Panda, S.P., Role of Thermal Degradation of Hybrid Rocket Fuels in Hypergolic

Risha, G.A., Boyer, E., Wehrman, R.B., and Kuo, K.K, Performance Comparison of HTPB-Based Solid Fuels Containing Nano-Sized Energetic Powder in a Cylindrical Hybrid Rocket Motor 38 th AIAA/ASME/SAE/ASEE Joint Propulsion Conference and Exhibit,7 10 July 2002.

Risha, G.A., Ulas A., Boyer, E., Kumar, S., and and Kuo, K.K, Combustion of HTPB-Based Solid Fuels Containing Nano-Sized Energetic Powder in a Hybrid Rocket Motor, 37th AIAA/ASME/SAE/ASEE Joint Propulsion Conference and Exhibit, 811 July, 2001.

Sparks, D.S., Hybrid Propellants from Lunar Material, Acta Astronáutica, Vol. 17, No. 10, pp. 10931097, 1988. 